\title{
Arsenic speciation in edible alga samples by microwave-assisted extraction and high performance liquid chromatography coupled to atomic fluorescence spectrometry
}

\author{
S. García-Salgado, M.A. Quijano*, M.M. Bonilla \\ Departamento de Ingeniería Civil Tecnología Hidráulica y Energética, Escuela Universitaria de Ingeniería Técnica de Obras Públicas, Universidad Politécnica de Madrid, Alfonso XII 3 \\ y 5, 28014 Madrid, Spain
}

Keywords:

Arsenic speciation

Microwave-assisted extraction

Edible algae

Inductively coupled plasma atomic

emission spectrometry

High performance liquid chromatography

Hydride generation-atomic fluorescence

spectrometry

\begin{abstract}
A B S T R A C T
Twelve commercially available edible marine algae from France, Japan and Spain and the certified reference material (CRM) NIES No. 9 Sargassum fulvellum were analyzed for total arsenic and arsenic species. Total arsenic concentrations were determined by inductively coupled plasma atomic emission spectrometry (ICP-AES) after microwave digestion and ranged from 23 to $126 \mu \mathrm{gg}^{-1}$. Arsenic species in alga samples were extracted with deionized water by microwave-assisted extraction and showed extraction efficiencies from 49 to $98 \%$, in terms of total arsenic. The presence of eleven arsenic species was studied by high performance liquid chromatography-ultraviolet photo-oxidation-hydride generation atomic-fluorescence spectrometry (HPLC-(UV)-HG-AFS) developed methods, using both anion and cation exchange chromatography. Glycerol and phosphate sugars were found in all alga samples analyzed, at concentrations between 0.11 and $22 \mu \mathrm{gg}^{-1}$, whereas sulfonate and sulfate sugars were only detected in three of them (0.6-7.2 $\left.\mu \mathrm{g} \mathrm{g}^{-1}\right)$. Regarding arsenic toxic species, low concentration levels of dimethylarsinic acid (DMA) $\left(<0.9 \mu \mathrm{gg}^{-1}\right.$ ) and generally high arsenate (As(V)) concentrations (up to $77 \mu \mathrm{g} \mathrm{g}^{-1}$ ) were found in most of the algae studied. The results obtained are of interest to highlight the need to perform speciation analysis and to introduce appropriate legislation to limit toxic arsenic species content in these food products.
\end{abstract}

\section{Introduction}

Arsenic occurs in seawater mainly as inorganic arsenic (arsenite, As(III), and arsenate, As(V)) at low $\mu \mathrm{g} \mathrm{L}^{-1}$ level [1]. However, some marine organisms accumulate arsenic; thus, they often have much higher arsenic concentrations than in the surrounding environment, typically in the range of $10-100 \mu \mathrm{g} \mathrm{g}^{-1}$ [2], even though arsenic has been reported to be mostly biotransformed into less toxic organic arsenic compounds [3]. Arsenobetaine (AsB) has been the major arsenic species found in marine fauna, while in algae the most frequently occurring arsenic species are arsenosugars, especially the derivatives of dimethylarsonylribosides commonly named glycerol, phosphate, sulfonate and sulfate sugars [4-8], whose structures are shown in Fig. 1. Besides these species, others like monomethylarsonic acid (MMA), dimethylarsinic acid (DMA), trimethylarsine oxide (TMAO), tetramethylarsonium ion (TETRA), arsenocholine (AsC) and some inorganic arsenic ( $\mathrm{As}(\mathrm{III})$ and $\mathrm{As}(\mathrm{V})$ ) can be found in marine organisms as well [9-12].
Toxicity studies of arsenic have shown that different forms exhibit different toxicities, thus inorganic arsenic species are more toxic than organic compounds and toxicity generally decreases with increasing degree of methylation, with the exception of TETRA species [13]. Arsenosugars are assumed to be much less toxic than inorganic arsenic species [14], although their toxicity has not been well assessed [15]. However, studies based on the presence of arsenic metabolites in humans point to indirect toxicity resulting from the ingestion of algae containing arsenosugars, due to their biotransformation in toxic arsenicals [16]. Since arsenic species have different toxicity, information about the distribution of the species within algae is necessary for assessing the risk associated with the entry of arsenic into the wildlife and human food chains. Therefore, there is considerable interest in developing analytical methodologies for arsenic speciation in food products. This interest is accentuated in the case of algae, because it is well known that they contribute substantial amounts of arsenic to the human diet, and their consumption is nowadays increasing due to their properties as food additives, nutritional values (high contents of iodine, minerals and vitamins) and suggested medical applications [17].

Detailed information concerning analytical methods for arsenic speciation can be found in several reviews [17-20]. High performance liquid chromatography-inductively coupled plasma 

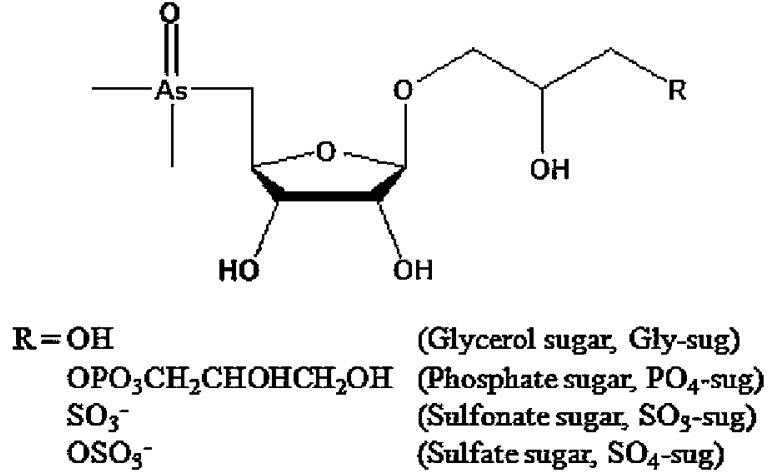

Fig. 1. Structures of the four most common arsenosugars found in algae.

mass spectrometry (HPLC-ICP-MS) is the most frequently used hyphenated technique for arsenic speciation [5-7,11,12,21]. However, the hydride generation-atomic fluorescence spectrometry (HG-AFS) coupled to HPLC represents a suitable alternative to this technique $[22,23]$. HG-AFS has been reported to be similar to inductively coupled plasma mass spectrometry (ICP-MS) regarding sensitivity and linear calibration range, although it has some advantages for arsenic speciation analysis, such as simplicity, lower acquisition and running costs [24-26]. However, the destruction of the organic part of arsenic species is required to determine them by HG-AFS, as they do not generate volatile hydrides or because the generation efficiency is very low [27]. Photo-oxidation to convert these species into inorganic arsenic is achieved after chromatographic separation by using a strong oxidant $\left(\mathrm{K}_{2} \mathrm{~S}_{2} \mathrm{O}_{8}\right)$ in basic media and ultraviolet (UV) radiation emitted from a low pressure mercury lamp. Regarding arsenic species separation, ion-exchange chromatography is preferred for coupling to HG-AFS detection, as the separation process is more reproducible and less prone to sample matrix interferences than ion-paring chromatography [22]. On the other hand, both anion and cation exchange chromatography is needed for arsenic speciation in biological samples, due to the different ionic character of aqueous soluble arsenic species. The mobile phases commonly used are phosphate and pyridine solutions, for anion and cation exchange, respectively. HPLC-(UV)-HG-AFS have been successfully applied to a great variety of samples. For example, Šlejkovec et al. [28] analyzed six CRMs of biological origin (dogfish muscle and liver, lobster hepatopancreas, oyster tissue, brown algae and scallop) by HPLC-(UV)-HG-AFS, using both anion and cation exchange chromatography methods. They identified AsB, DMA, TETRA, AsC, TMAO, As(V), MMA and two arsenosugars, together with four unidentifiable compounds (one in brown algae, one in dogfish muscle and liver and lobster hepatopancreas, and two in scallop). In 2002, Sánchez-Rodas et al. [29] applied this same hyphenated technique for the analysis of aqueous extracts of oysters. These authors concluded that it is an alternative technique to liquid chromatography-electrospray-mass spectrometry (LC-ESMS) for the detection of arsenosugars in crude extracts, since signal response in HPLC-(UV)-HG-AFS is little influenced by the sample matrix, whereas LC-ES-MS analysis usually requires previous sample clean-up steps. Schaeffer et al. [30] determined twelve arsenic compounds in mussels, anchovies, seabreams, sea bass and sardines by HPLC-(UV)-HG-AFS, using both anion and cation exchange methods. AsB was detected as the major compound in all the samples, with trace amounts of As(III), DMA and AsC, whereas arsenosugars were detected only in mussel samples. Šlejkovec et al. [31] applied it for the determination of arsenic species in ten different marine algae (red, green and brown) from the littoral zone along the Adriatic Sea coast of Slovenia. They found that arsenosugars were the most abundant arsenicals in most of the analyzed algae, although they also found AsB, As(III), As(V) and DMA, As(V) being the major species in three alga samples (Ceranium sp., Polisyphonia sp., Cystoseira barbata). In 2009, Geng et al. [32] compared the performance of the combination of solvent extraction and HPLC-(UV)-HG-AFS with the combination of alkaline digestion and cryogenic trap-hydride generation-atomic absorption spectrometry (CT-HG-AAS), for arsenic speciation in marine product samples. They analyzed six CRMs of marine animal samples and four seaweed samples, and concluded that results obtained by both methodologies are comparable, because the concentrations of arsenobetaine obtained in CRMs from the extraction-HPLC method were very consistent with those of trimethylated arsenic species measured by the digestion-CT method. In the case of seaweed samples, the amounts of dimethylated arsenic species measured by the digestion-CT method were approximately equal to the sum of the amounts of DMA and three arsenosugars determined by the extraction-HPLC method.

The aims of this work consisted on: (1) the development of arsenic speciation analysis methods based on the coupling of high performance liquid chromatography (anion and cation exchange) with ultraviolet photo-oxidation-hydride generation-atomic fluorescence spectrometry (HPLC-(UV)-HG-AFS); (2) the application of the developed methods to carry out the identification and quantification of arsenic species present in the water extracts, obtained by microwave-assisted extraction, of commercially available edible alga samples.

\section{Materials and methods}

\subsection{Instrumentation}

Microwave assisted extraction was conducted using a MARS 5 microwave oven (CEM, Matthews, NC, USA), with Pyrex extraction vessels. The temperature was monitored in a control vessel by an armored fiber-optic temperature control probe.

An ETHOS 1 closed vessel microwave digestion system (Milestone S.r.l., Sorisole, BG, Italy), with built-in ATC-400-CE automatic temperature control and employing TFM-Teflon microwave vessels, was used for alga samples digestion.

Total arsenic determination was performed with an inductively coupled plasma atomic emission spectrometer (ICP-AES) model Liberty Series II Axial Sequential (Varian Australia, Mulgrave, Australia).

For arsenic speciation analysis, the HPLC-(UV)-HG-AFS system used consists of a Jasco PU-2089 plus quaternary gradient pump (Jasco, Tokyo, Japan) and a Rheodyne 7725 six-port sample injection valve, fitted with a $100 \mu \mathrm{l}$ sample loop (Rheodyne, CA, USA). Chromatographic separations were carried out in a Hamilton PRP-X100 $(250 \mathrm{~mm} \times 4.1 \mathrm{~mm}, 10 \mu \mathrm{m})$ anion exchange column and in a Hamilton PRP-X200 $(250 \mathrm{~mm} \times 4.1 \mathrm{~mm}, 10 \mu \mathrm{m})$ cation exchange column (Phenomenex, Torrance, CA, USA). The corresponding guard columns ( $25 \mathrm{~mm} \times 2.3 \mathrm{~mm}, 12-20 \mu \mathrm{m}$ ) (Phenomenex) were used in order to preserve the analytical columns. The column outlet was coupled to a 10.570 UV Cracker (PS Analytical), used for the destruction of the organic part of the arsenic compounds, followed by a PSA 10004 continuous-flow vapor system (PS Analytical, Sevenoaks, Kent, UK), equipped with a B-type gas-liquid separator and a Perma Pure drier tube (PS Analytical). The hydrides generated were transported through a stream of argon to a PS Analytical Millennium Excalibur atomic fluorescence spectrometer PSA 10.055 , equipped with a boosted discharge hollow cathode lamp (BDHCL) (Superlamp, Photon, Victoria, Australia) as an AFS excitation source, a hydrogen diffusion flame as the atomization cell and specific filters (multireflectance filters) to achieve isolation and reduction of flame emission. 
Other equipment used included a Binder GmbH ED53 drying oven (Tuttlingen, Germany), used to dry the samples; a Retsch MM 301 mixer mill (Haan, Germany) with tungsten carbide grinding jars and balls, used to grind the samples; and an Eppendorf $5804 \mathrm{R}$ centrifuge (Hamburg, Germany), used for the centrifugation of the alga extracts.

\subsection{Reagents and standard solutions}

All solutions were prepared from analytical reagent grade chemicals using deionized water obtained from a Millipore water purification system (Elix ${ }^{\circledR}$, Molsheim, France).

As(III) (994 $\left.\pm 2 \mathrm{mg} \mathrm{L}^{-1}\right)$ and As(V) (1000 $\left.\mathrm{mg} \mathrm{L}^{-1}\right)$ stock standard solutions were purchased from Fluka (Sigma-Aldrich, Steinheim, Germany) and Merck (Darmstadt, Germany), respectively. $1000 \mathrm{mg} \mathrm{L}^{-1}$ standard solutions of MMA, DMA, AsB, TETRA and TMAO were prepared by dissolving the appropriate amounts of $\mathrm{CH}_{3} \mathrm{AsO}_{3} \mathrm{Na}_{2}$ (MMA) purchased from Supelco (Bellefonte, PA, USA); $\mathrm{C}_{2} \mathrm{H}_{6} \mathrm{AsNaO}_{2} \cdot 3 \mathrm{H}_{2} \mathrm{O}$ (DMA) from Fluka; $\mathrm{AsC}_{5} \mathrm{H}_{11} \mathrm{O}_{2}$ (AsB) from TCLC (Tri Chemical Laboratories Inc., Yamanashi, Japan); and $\mathrm{AsC}_{4} \mathrm{H}_{12} \mathrm{Br}$ (TETRA) and $\mathrm{AsC}_{3} \mathrm{H}_{9} \mathrm{O}$ (TMAO) from Argus Chemicals srl (Vernio, PO, Italy). All the stock solutions were kept at $4^{\circ} \mathrm{C}$, and further diluted solutions for the analysis were prepared daily. Yttrium stock standard solution ( $1000 \mathrm{mg} \mathrm{L}^{-1}$ ), purchased from Fluka, was used as an internal standard for ICP-AES total arsenic analysis. The As(V) stock standard solution was used for both total As calibration in ICP-AES and As(V) species calibration in HPLC-(UV)-HG-AFS.

An aliquot freeze-dried extract of Fucus serratus, kindly donated by Prof. Kevin A. Francesconi (Department of Analytical Chemistry, Institute of Chemistry, Karl-Franzens University Graz, Graz, Austria) [33], containing the four common arsenosugars (glycerol (Gly-sug), phosphate ( $\mathrm{PO}_{4}$-sug), sulfonate $\left(\mathrm{SO}_{3}\right.$-sug) and sulfate ( $\mathrm{SO}_{4}$-sug) sugars), was used to assign the arsenosugar peaks in the chromatograms and for their concentration estimation in the alga extracts. The extract was dissolved in $4.0 \mathrm{~mL}$ of deionized water, the concentration of the four above mentioned arsenosugars being $25,21.5,155$ and $100 \mu \mathrm{g} \mathrm{L}^{-1}$ of arsenic per species, respectively.

The 5, 20 and $100 \mathrm{mmol} \mathrm{L}^{-1}$ phosphate buffers used as mobile phases for anion exchange chromatographic method were prepared by dissolving appropriate amounts of $\mathrm{K}_{2} \mathrm{HPO}_{4}$ and $\mathrm{KH}_{2} \mathrm{PO}_{4}$ (Scharlau, Barcelona, Spain) and mixing the solutions until $\mathrm{pH} 9.0$ was reached. A $2.5 \mathrm{mmol} \mathrm{L}^{-1}$ pyridine solution (Sigma-Aldrich) at $\mathrm{pH} 2.65$ adjusted with hydrochloric acid (Scharlau) was used for cation exchange chromatographic method. The mobile phases were filtered through a $0.45 \mu \mathrm{m}$ Magna nylon filters (Osmonics Inc., Minnetonka, MN, USA) and degassed before use by ultrasonic shaking. Furthermore, the alga extracts were filtered through $0.22 \mu \mathrm{m}$ nylon syringe filters (Osmonics) before their injection in the HPLC system.

Sodium borohydride solution $1.4 \%(\mathrm{w} / \mathrm{v})$ was prepared by dissolving $\mathrm{NaBH}_{4}$ powder (Aldrich, Milwaukee, WI, USA) in deionized water and stabilizing it with $0.1 \mathrm{~mol} \mathrm{~L}^{-1}$ sodium hydroxide (Fluka). It was prepared daily and filtered before use. Hydrochloric acid solution $\left(8.0 \mathrm{~mol} \mathrm{~L}^{-1}\right)$ was prepared by dilution of $\mathrm{HCl} 37 \%$ (Scharlau). Both solutions were used in the hydride generation step.

Potassium peroxodisulfate solutions 2 and $4 \%(w / v)$, stabilized in 2 and $4 \%(\mathrm{w} / \mathrm{v})$ sodium hydroxide, respectively, used as oxidizing agents in the photo-oxidation step, were prepared daily from $\mathrm{K}_{2} \mathrm{~S}_{2} \mathrm{O}_{8}$ (Scharlau) and $\mathrm{NaOH}$ and filtered before use.

Nitric acid (69.5\%) and hydrogen peroxide (35\%), both from Scharlau, were used to digest the samples.

\subsection{Alga samples}

Edible alga samples from Spain and Japan were purchased at local markets as dried products, ground to a fine powder in a tungsten carbide disc mill and kept into pre-cleaned polyethylene containers at room temperature for subsequent analyses. The samples include four Atlantic algae harvested by the local manufacturer in Galician coast (Northwest Spain): Himanthalia elongata (Sea spaghetti), Laminaria ochroleuca (Kombu), Undaria pinnatifida (Wakame) and Porphyra umbilicalis (Nori). Furthermore, the edible alga samples from Japan: Eisenia arborea (Arame), Hizikia fusiformis (Hijiki), L. ochroleuca (Kombu), U. pinnatifida (Wakame) and $P$. umbilicalis (Nori) were also analyzed, together with three alga samples from France (Fucus vesiculosus (Fucus), L. ochroleuca (Kombu) and Laminaria digitata (Laminaria)), donated by the Centre d'Etude et de Valorisation des Algues (Pleubian, France).

The reference material NIES No.9, from the National Institute for Environmental Studies (Tsukuba, Ibaraki, Japan) and certified for total arsenic $\left(115 \pm 9 \mu \mathrm{g} \mathrm{g}^{-1}\right)$, was a lyophilized Sargasso material (Sargassum fulvellum) and was used for quality control purposes.

\subsection{Experimental}

\subsubsection{Sample treatment}

Total arsenic concentration in alga samples was determined by ICP-AES after microwave digestion with nitric acid and hydrogen peroxide, following a method previously developed for total arsenic determination in plant samples [34].

Arsenic species were extracted in deionized water $(8 \mathrm{~mL}$ per $200 \mathrm{mg}$ of alga sample) following a previously developed microwave-assisted extraction method [10]. The extraction process (heating at $90^{\circ} \mathrm{C}$ for $5 \mathrm{~min}$ ) was repeated three times. The extracts were centrifuged at $14,000 \times g$ for $10 \mathrm{~min}$ and the three supernatants were mixed, diluted up to $25 \mathrm{~mL}$ with deionized water and centrifuged again. Total arsenic concentration extracted was determined by ICP-AES, using the experimental conditions previously optimized [34]. Prior to the chromatographic analysis, final alga extracts were filtered through $0.22 \mu \mathrm{m}$ nylon syringe filters.

\subsubsection{Chromatographic separation and detection}

The identification and quantification of arsenic species in alga extracts was carried out by HPLC-(UV)-HG-AFS. The separation of arsenic compounds was performed by two chromatographic methods, based on anion and cation exchange chromatography. The chromatographic separation of As(III), As(V), MMA, DMA and four arsenosugars (Gly-sug, $\mathrm{PO}_{4}$-sug, $\mathrm{SO}_{3}$-sug and $\mathrm{SO}_{4}$-sug) was carried out by injecting solutions containing the eight compounds onto the anion exchange column (Hamilton PRP-X100) and initially eluting with $5 \mathrm{mmol} \mathrm{L}^{-1}$ phosphate buffer of $\mathrm{pH} \mathrm{9.0,} \mathrm{at} \mathrm{a} \mathrm{flow}$ rate of $1.0 \mathrm{~mL} \mathrm{~min}^{-1}$. After $1 \mathrm{~min}$, the mobile phase was changed to $20 \mathrm{mmol} \mathrm{L}^{-1}$ phosphate buffer of $\mathrm{pH} 9.0$, using a linear concentration gradient over a 0.1 -min period. Finally, after $5 \mathrm{~min}$, the mobile phase was changed to $100 \mathrm{mmol} \mathrm{L}^{-1}$ phosphate buffer of $\mathrm{pH} 9.0$, using the same linear concentration gradient. The eluted arsenic species were conducted to an on line photo-oxidation system, equipped with a UV lamp and a $2 \%(\mathrm{w} / \mathrm{v})$ potassium persulfate solution in $2 \%(\mathrm{w} / \mathrm{v}) \mathrm{NaOH}$, at a flow rate of $0.5 \mathrm{~mL} \mathrm{~min}^{-1}$. Arsenic species were detected by HG-AFS, using the operation conditions given in Table 1.

The separation of As(III), As(V), AsB, TETRA and TMAO was performed on a Hamilton PRP-X200 cation exchange column and using pyridine $2.5 \mathrm{mmol} \mathrm{L}^{-1}$ at $\mathrm{pH} 2.65$ (adjusted with $\mathrm{HCl}$ ) as mobile phase, at a flow rate of $1.0 \mathrm{~mL} \mathrm{~min}{ }^{-1}$. The eluted arsenic species were detected by (UV)-HG-AFS, using a $4 \%(\mathrm{w} / \mathrm{v})$ potassium persulfate solution in $4 \%(\mathrm{w} / \mathrm{v}) \mathrm{NaOH}$. The operation conditions are given in Table 1.

Atomic fluorescence signals were assessed with Clarity chromatographic software (DataApex Ltd., Prague, Czech Republic). The analytical peaks obtained were evaluated in terms of peak area by external standard calibration. Arsenic species in alga samples were 
Table 1

Experimental conditions for arsenic speciation by HPLC-(UV)-HG-AFS.

\begin{tabular}{|c|c|}
\hline \multicolumn{2}{|l|}{ HPLC } \\
\hline \multicolumn{2}{|l|}{ Anion exchange (concentration gradient): } \\
\hline Column & Hamilton PRP-X100 \\
\hline Mobile phase & $\begin{array}{l}\text { Phosphate buffer } 5,20 \text { and } \\
100 \mathrm{mmol} \mathrm{L}^{-1} \text {, pH } 9.0\end{array}$ \\
\hline \multicolumn{2}{|l|}{ Cation exchange (isocratic): } \\
\hline Column & Hamilton PRP-X200 \\
\hline Mobile phase & $\begin{array}{l}\text { Pyridine } 2.5 \mathrm{mmol} \mathrm{L}^{-1}, \mathrm{pH} \\
2.65(\mathrm{HCl})\end{array}$ \\
\hline Flow rate $\left(\mathrm{mL} \mathrm{min}^{-1}\right)$ & 1.0 \\
\hline Injection volume $(\mu \mathrm{L})$ & 100 \\
\hline \multicolumn{2}{|l|}{ On line UV lamp } \\
\hline UV lamp & $\begin{array}{l}\text { 10.570 UV Cracker (PS } \\
\text { Analytical) }\end{array}$ \\
\hline UV cracking frequency $(\mathrm{Hz})$ & 50 \\
\hline UV cracking voltage $(\mathrm{V})$ & 230 \\
\hline \multirow[t]{2}{*}{$\mathrm{K}_{2} \mathrm{~S}_{2} \mathrm{O}_{8}(\%, w / v)$} & $2^{\mathrm{a}}$ \\
\hline & $4^{\mathrm{b}}$ \\
\hline $\mathrm{K}_{2} \mathrm{~S}_{2} \mathrm{O}_{8}$ flow rate $\left(\mathrm{mL} \mathrm{min}^{-1}\right)$ & 0.5 \\
\hline \multicolumn{2}{|l|}{ Hydride generation } \\
\hline $\mathrm{HCl}\left(\mathrm{molL}^{-1}\right)$ & 8.0 \\
\hline $\mathrm{HCl}$ flow rate $\left(\mathrm{mL} \mathrm{min}^{-1}\right)$ & 1.4 \\
\hline $\mathrm{NaBH}_{4}(\%, \mathrm{w} / \mathrm{v})$ & 1.4 \\
\hline $\mathrm{NaBH}_{4}$ flow rate $\left(\mathrm{mL} \mathrm{min}^{-1}\right)$ & 1.4 \\
\hline Ar (GL separator) flow rate $\left(\mathrm{mL} \mathrm{min}{ }^{-1}\right)$ & 250 \\
\hline Air (drying) flow rate $\left(\mathrm{L} \mathrm{min}^{-1}\right)$ & 2.5 \\
\hline \multicolumn{2}{|l|}{ AFS instrument } \\
\hline Detector & $\begin{array}{l}\text { Millennium Excalibur (PS } \\
\text { Analytical) }\end{array}$ \\
\hline Wavelength (nm) & 193.7 \\
\hline Primary current (mA) & 27.5 \\
\hline Boost current (mA) & 35.0 \\
\hline Gain & 10 and 100 \\
\hline
\end{tabular}

a For the anion exchange method.

${ }^{\mathrm{b}}$ For the cation exchange method.

identified due to the increase in their areas when arsenic species standard solutions were added, except for arsenosugars, which were identified by their retention time in the $F$. serratus extract solution and alga sample extracts. The instrument drift was checked by injection of a standard solution every two samples injections.

\subsubsection{Stability of arsenic species during the extraction procedure}

Hijiki ( $H$. fusiformis) sample was spiked with a mixture of the three arsenic species (AsB, TETRA and TMAO). A portion of $200 \mathrm{mg}$ of the alga was weighed and $1 \mathrm{~mL}$ of stock solution containing $10 \mathrm{mg} \mathrm{L}^{-1}$ (as arsenic) of each one of the three species was added. The mixture was remained overnight. The spiked sample was processed by the extraction procedure previously described and arsenic species were analyzed by cation exchange HPLC-(UV)-HG-AFS.

\section{Results and discussion}

\subsection{Determination of total arsenic in alga samples}

Total arsenic concentrations in alga samples were determined by ICP-AES. Table 2 shows the results obtained in the total arsenic determination, expressed in terms of dry weight (dw), for the twelve alga samples analyzed (10 brown algae and 2 red algae). The accuracy of the method was assessed by using the CRM NIES No. 9, S. fulvellum (Sargasso). The result obtained $\left(109 \pm 2 \mu \mathrm{gg}^{-1}\right.$ ) showed the absence of significant differences, at the $95 \%$ confidence level, between the As concentration found and the certified value $\left(115 \pm 9 \mu \mathrm{gg}^{-1}\right)$. Therefore, the analytical method used has proven to be suitable for total arsenic determination in alga samples. The total arsenic concentrations found in alga samples varied over a wide range $\left(23-126 \mu \mathrm{gg}^{-1}\right)$, which is in agreement with those reported in the bibliography for edible algae $\left(8-150 \mu \mathrm{gg}^{-1}\right)$
Table 2

Concentrations expressed as $\mu \mathrm{gg}^{-1}$ on dry mass (mean $\pm \mathrm{SD}, n=3$ ) of total arsenic found in commercially available edible marine alga samples after microwave digestion and determination by ICP-AES.

\begin{tabular}{llllr}
\hline Division & Species & Common name & Origin & Total As \\
\hline $\begin{array}{l}\text { Phaeophyta } \\
\text { (brown algae) }\end{array}$ & Eisenia arborea & Arame & Japan & $26 \pm 1$ \\
& Fucus vesiculosus & Fucus & France & $47 \pm 2$ \\
& Himanthalia elongata & Sea spaghetti & Spain & $24 \pm 2$ \\
& Hizikia fusiformis & Hijiki & Japan & $98 \pm 5$ \\
& Laminaria ochroleuca & Kombu & France & $42 \pm 5$ \\
& & & Japan & $97 \pm 6$ \\
& Laminaria digitata & Laminaria & Spain & $46 \pm 4$ \\
& Undaria pinnatifida & Wakame & $126 \pm 5$ \\
& & Japan & $37 \pm 2$ \\
Rhodophyta & Porphyra umbilicalis & Nori & Spain & $37 \pm 1$ \\
(red algae) & & & Japan & $23 \pm 3$ \\
& & & Spain & $34 \pm 3$ \\
\hline
\end{tabular}

[35-37]. The highest arsenic concentrations were found in the brown algae Laminaria from France $\left(126 \mu \mathrm{g} \mathrm{g}^{-1}\right)$, followed by Hijiki and Kombu algae from Japan (both about $100 \mu \mathrm{gg}^{-1}$ ), whereas the lowest arsenic concentration levels were found in the red alga Nori from Japan $\left(23 \mu \mathrm{gg}^{-1}\right)$, and the brown algae Sea spaghetti from Spain $\left(24 \mu \mathrm{gg}^{-1}\right)$ and Arame from Japan $\left(26 \mu \mathrm{gg}^{-1}\right)$. From the results, total arsenic contents in Phaeophytes (brown algae) were generally higher than in Rhodophytes (red algae), which is in agreement with several authors that reported a relationship between arsenic content and algal division, so that brown>red $>$ green [36,38].

Regarding the comparison between the results obtained for the same alga species from different origins, similar arsenic concentration levels were found between the two Wakame samples ( $37 \mu \mathrm{g} \mathrm{g}^{-1}$, for both Japanese and Spanish algae), as well as for the two Nori algae (23 and $34 \mu \mathrm{g} \mathrm{g}^{-1}$, for the samples from Japan and Spain, respectively). However, in the three Kombu samples, it was observed that algae from France and Spain have similar arsenic levels, whereas the sample from Japan presented a concentration approximately two times higher. From these results, a relationship between the arsenic concentration levels and the alga species or their origin cannot be established. Algae absorb arsenic directly from sea water and there are some factors influencing the arsenic levels in these marine organisms, such as the light intensity, turbidity, temperature, depth, salinity and nutrient uptake [21]. These factors may contribute to the differences observed in total arsenic concentration levels in the algae studied.

\subsection{Arsenic species determination by HPLC-(UV)-HG-AFS}

The choice of strong ion-exchange HPLC for arsenic species separation was based in our previous experience in the arsenic speciation field $[9,10,39]$, as well as in the consulted bibliography $[21,31,32]$.

The anion exchange chromatographic method developed led us to the separation of eight arsenic species in less than $17 \mathrm{~min}$. A chromatogram obtained for a mixture of Gly-sug, As(III), DMA, $\mathrm{PO}_{4}{ }^{-}$ sug, MMA, $\mathrm{SO}_{3}$-sug, $\mathrm{As}(\mathrm{V})$ and $\mathrm{SO}_{4}$-sug is shown in Fig. 2a. Cationic arsenic species (AsB, TETRA and TMAO) coeluted in the dead volume of the system $(3.8 \pm 0.1 \mathrm{~mL})$, very close to Gly-sug pecies, as it can be observed in Fig. 2a (dashed line). Therefore, the optimization of a cation exchange chromatographic method was needed for the differentiation between Gly-sug and these cationic arsenic species.

The cation exchange chromatographic method developed led us to the separation of As(III), As(V), AsB, TETRA and TMAO species in less than $14 \mathrm{~min}$. The chromatogram obtained is shown in Fig. 2b. The species As(III) eluted in the dead volume, and therefore 

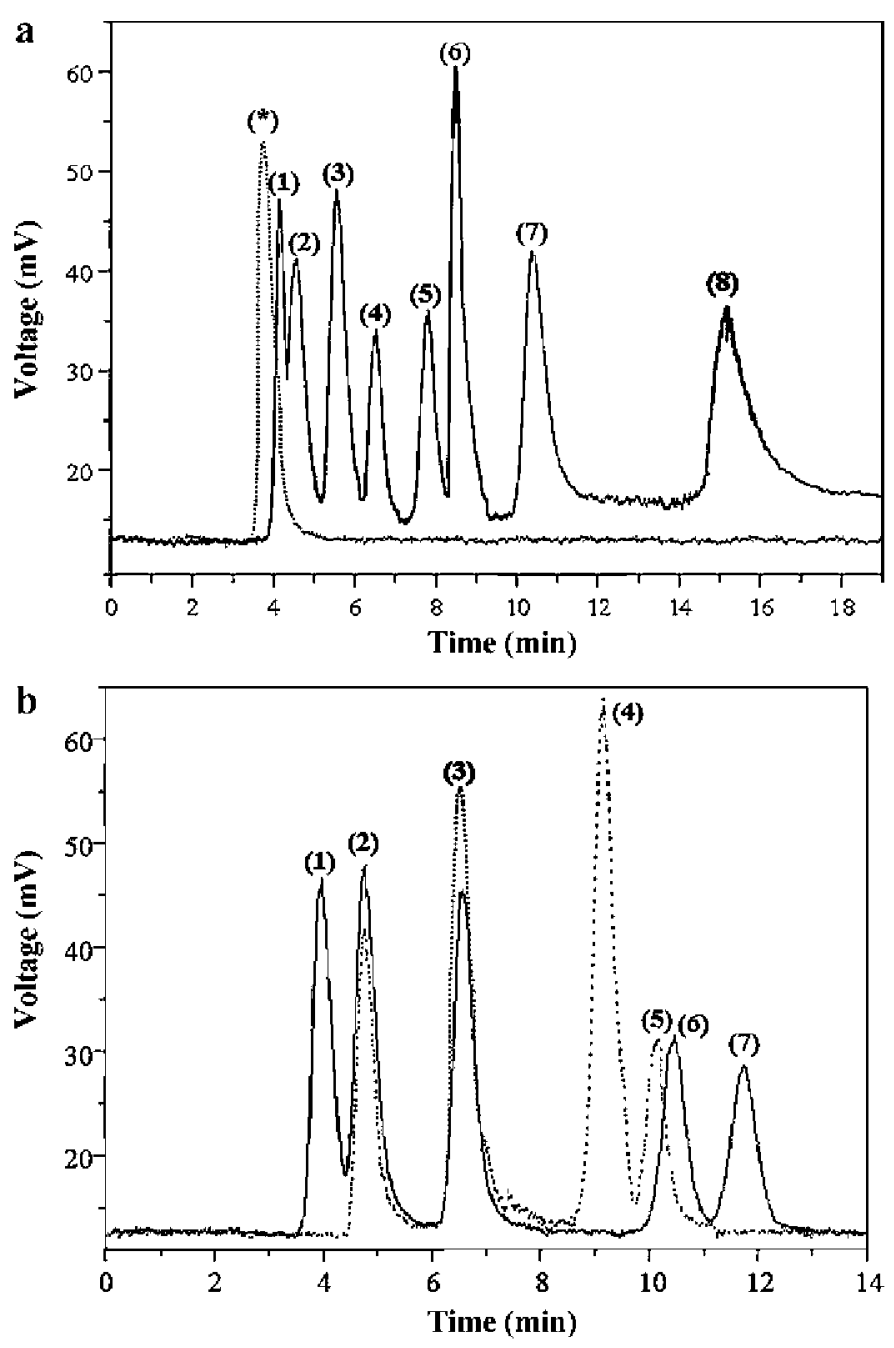

Fig. 2. (a) Chromatogram obtained by anion exchange HPLC-(UV)-HG-AFS (gain 10 ) for a mixture of $\mathrm{As}(\mathrm{III})$, As(V), DMA and MMA (25 $\left.\mu \mathrm{g} \mathrm{L}^{-1} \mathrm{As}\right)$ and Gly, $\mathrm{PO}_{4}, \mathrm{SO}_{3}$ and $\mathrm{SO}_{4}$-Sug $\left(25,21.5,155\right.$ and $100 \mu \mathrm{g} \mathrm{L}^{-1}$ As, respectively): (1) Gly-Sug, (2) As( III), (3) DMA, (4) $\mathrm{PO}_{4}$-sug, (5) MMA, (6) $\mathrm{SO}_{3}-\mathrm{sug}$, (7) As(V), and (8) $\mathrm{SO}_{4}$-sug. ( $\left.{ }^{*}\right) \mathrm{AsB}\left(25 \mu \mathrm{g} \mathrm{L}^{-1}\right.$ As). (b) Chromatogram obtained by cation exchange HPLC-(UV)-HG-AFS (gain 10) for a mixture of As(III), As(V), MMA, DMA, AsB, TETRA and TMAO (25 $\mu \mathrm{g} \mathrm{L}^{-1}$ As): (1) As( III) + MMA, (2) As(V) + DMA, (3) AsB, (6) TETRA and (7) TMAO. Chromatogram for Fucus serratus extract (dashed line): (2) $\mathrm{PO}_{4}$-sug, (3) $\mathrm{SO}_{4}$-sug, (4) $\mathrm{SO}_{3}-\mathrm{sug}$, and (5) Gly-sug $\left(21.5,100,155\right.$ and $25 \mu \mathrm{g} \mathrm{L}^{-1}$ As, respectively).

coeluted with the arsenic species MMA, whereas the species $\mathrm{As}(\mathrm{V})$ coeluted with the arsenic species DMA, which can be differed by the anion exchange method. Regarding arsenosugars, the injection of an extract from the seaweed F. serratus [33] (Fig. 2b, dashed line) allowed us to verify that at the $\mathrm{pH}$ used in this method (2.65), these arsenic species behave like cations, so they are retained in the column [6]. The species $\mathrm{PO}_{4}$-sug and $\mathrm{SO}_{4}$-sug coeluted with the species $\mathrm{As}(\mathrm{V})$ and $\mathrm{AsB}$, respectively, whereas $\mathrm{SO}_{3}$-sug and Glysug eluted between the species AsB and TETRA. In conclusion, both anion and cation exchange chromatographic methods are needed for the secure identification of the eleven arsenic species studied, especially when cationic arsenic species are present together with inorganic and arsenosugars species, although the AsB concentration could only be estimated by subtracting the $\mathrm{SO}_{4}$-sug concentration (determined by the anion exchange method) if both species are present in the sample.

Arsenic species determination was carried out by HG-AFS. It is generally accepted that organic arsenic species do not form hydrides, or form them with low hydride generation efficiencies [27]. Therefore, the introduction of a decomposition step before the hydride generation is necessary. In this study, an on line photooxidation was carried out using a UV lamp and a solution of potassium persulfate, prepared in sodium hydroxide. According to Šlejkovec et al. [28], the detector response depends on the degree of decomposition in the UV photo-oxidation step. Therefore, the effect of the potassium persulfate concentration was evaluated from 1 to $4 \%(w / v)$. A concentration of $2 \%(w / v)$ was chosen for the oxidation of organic arsenic species when they were separated by the anion exchange chromatographic method, due to the better signal/noise ratio obtained, whereas a higher concentration ( $4 \%(\mathrm{w} / \mathrm{v}))$ was needed when the cation exchange method was used. This fact can possibly be due to a part of the persulfate is consumed by the organic mobile phase used (pyridine), which is also oxidized during the photo-oxidation step. Hydride generation and AFS detection were achieved according to the experimental conditions shown in Table 1.

The analytical characteristics were evaluated for the two methods used. The precision, evaluated as relative standard deviation, was calculated from five independent replicates of a standard solution containing $10 \mu \mathrm{g} \mathrm{L}^{-1}$ of arsenic per species, whereas the LODs were calculated as three times the standard deviation obtained from ten replicates of the lowest standard used in the calibration curve, which was of $1 \mu \mathrm{gL}^{-1}$ of arsenic per species, except for arsenosugars, due to the absence of standard solutions of these species. In this case, \%RSD and LODs were estimated in the anion exchange method, using different dilutions of the $F$. serratus extract solution (see Table 3 footnote). The results obtained, for a detector gain of 100 , are shown in Table 3 .

\subsection{Arsenic speciation in alga samples}

Table 4 shows the total arsenic extracted in deionized water by the microwave extraction method for the twelve alga samples studied, as well as for the CRM NIES No. 9, S. fulvellum (Sargasso material). Extraction efficiencies, calculated as the ratio of total arsenic in the water extract to total arsenic in the algae, are also shown in Table 4 and ranged from 49 (for Wakame from Japan) to $98 \%$ (for Sargasso material). Most of the algae analyzed present a high percentage of arsenic compounds soluble in water, which was higher than $73 \%$ for 11 of the 13 samples analyzed. The results obtained are in agreement with the wide ranges of extraction

Table 3

Limits of detection, expressed as $\mu g g^{-1}$ of arsenic, and relative standard deviation, expressed as percentage, for arsenic species studied by anion and cation exchange HPLC-(UV)-HG-AFS, for a detector gain of 100.

\begin{tabular}{|c|c|c|}
\hline Chromatographic system/Compounds & $\operatorname{LOD}^{\mathrm{a}}\left(\mu g g^{-1}\right.$ As $)$ & $\operatorname{RSD}^{\mathrm{b}}(\%)$ \\
\hline \multicolumn{3}{|l|}{ Anion exchange } \\
\hline Gly-sug & 0.030 & 3.4 \\
\hline As(III) & 0.019 & 3.0 \\
\hline DMA & 0.007 & 2.6 \\
\hline $\mathrm{PO}_{4}$-sug & 0.048 & 3.9 \\
\hline MMA & 0.027 & 3.3 \\
\hline $\mathrm{SO}_{3}-\mathrm{sug}$ & 0.062 & 4.2 \\
\hline $\operatorname{As}(V)$ & 0.028 & 3.3 \\
\hline $\mathrm{SO}_{4}-\mathrm{Sug}$ & 0.076 & 4.6 \\
\hline \multicolumn{3}{|l|}{ Cation exchange } \\
\hline $\operatorname{As}(I I I)$ & 0.045 & 3.9 \\
\hline $\operatorname{As}(\mathrm{V})$ & 0.044 & 3.8 \\
\hline AsB & 0.033 & 3.4 \\
\hline TETRA & 0.067 & 4.5 \\
\hline TMAO & 0.064 & 4.4 \\
\hline
\end{tabular}

a Calculated for a standard solution containing $1 \mu \mathrm{g} \mathrm{L}^{-1}$ of As per species, except for arsenosugars (estimated by dilution of the $F$. serratus extract solution containing $2.5,2.15,1.5$ and $1.0 \mu \mathrm{g} \mathrm{L}^{-1}$ of As for Gly, $\mathrm{PO}_{4}, \mathrm{SO}_{3}$ and $\mathrm{SO}_{4}$-sug, respectively).

b Calculated from five independent replicates of a standard solution containing $10 \mu \mathrm{g} \mathrm{L}^{-1}$ of As per species, except for arsenosugars (estimated by dilution of the $F$. serratus extract solution containing $12.5,10.75,15$ and $10 \mu \mathrm{g} \mathrm{L}^{-1}$ of As for Gly, $\mathrm{PO}_{4}$, $\mathrm{SO}_{3}$ and $\mathrm{SO}_{4}$-Sug, respectively). 
efficiencies in water reported depending on the particular algae type $[10,19]$. On the other hand, the arsenic fraction not extracted with water could correspond to arsenic bound to compounds such as lipids and might account for up to $50 \%$ of total arsenic in algae [40].

Arsenic speciation studies were carried out by HPLC-(UV)-HG-AFS, by the two chromatographic methods developed. The lack of peak eluting in the dead volume of the chromatograms obtained by the anion exchange chromatographic method showed the absence of cationic arsenic species in the water alga extracts. This fact was confirmed by cation exchange chromatography. Therefore, the anion exchange method was appropriate to perform arsenic speciation analysis in the alga samples studied. Fig. 3 shows, as examples, the chromatograms obtained by the anion exchange method for the water extracts of the red alga Nori from Japan (Fig. 3a, at gain 10 for AFS detector), the brown algae Fucus from France (Fig. 3b, gain 10) and Hijiki from Japan (Fig. 3c, gain 100), and the NIES No. 9 Sargasso material (Fig. 3d, gain 100). Arsenic compounds identified in the edible alga samples studied comprised DMA, As $(V)$ and the four arsenosugars (Gly-sug, $\mathrm{PO}_{4}$-sug, $\mathrm{SO}_{3}$-sug and $\mathrm{SO}_{4}$-sug), depending on the kind of algae analyzed. The arsenic species As(III), MMA, AsB, TMAO and TETRA were not detected in any alga sample studied, because either no chromatographic peak matched the corresponding retention time (for As(III) and MMA) or was found in the dead volume of the anion exchange method (for AsB, TMAO and TETRA).

Species quantification by HPLC-(UV)-HG-AFS was carried out by external calibration and the standard additions method, except for arsenosugars due the lack of standard solutions of these species. For the rest of the arsenic species studied, no matrix effects were found due to the absence of significant differences, at the $95 \%$ confidence level, between the calibration slopes obtained by both calibration methods. Arsenosugar concentrations were estimated by external calibration, both by using two different dilutions of the F. serratus extract solution (diluted 2 and 4 times) and by calibration against the nearest neighboring peak of a standard As species, which were DMA for Gly-sug and $\mathrm{PO}_{4}$-sug, MMA for $\mathrm{SO}_{3}$-sug, and $\mathrm{As}(\mathrm{V})$ for $\mathrm{SO}_{4}$-sug. The results of species quantification are shown in Table 4.

From the results, arsenate was found in all alga samples studied (2-80 $\left.\mu \mathrm{g} \mathrm{g}^{-1}\right)$, with the exception of both Nori samples, and represents between 8 and $84 \%$ of total As extracted. Therefore, the red algae Nori are the only alga samples between those studied where arsenate was not detected (Fig. 3a), which is in agreement with
Wei et al. [8], who did not detect $\mathrm{As}(\mathrm{V})$ in the $\mathrm{H}_{2} \mathrm{O} / \mathrm{MeOH}$ extracts of different Porphyra algae originating from China. However, a relationship between the alga division (brown or red) and the presence of arsenate could not be established since some authors reported its presence in families different from Porphyra, such as Laurencia sp., Ceramium sp. and Polisyphonia sp., belonging to Rhodophyta alga division $[7,31]$. On the other hand, DMA was identified in eight of the alga samples studied, but always in low concentration levels and below 3\% of the extracted As. It is remarkable that DMA was found in the five alga samples from Japan, although it was not detected or quantified in any of the four samples from Spain. Regarding arsenosugars, Gly-sug and $\mathrm{PO}_{4}$-sug were found in all the analyzed alga samples, whereas $\mathrm{SO}_{3}$-sug and $\mathrm{SO}_{4}$-sug were detected only in three samples. Gly-sug concentrations ranged from 1 to $14 \mu \mathrm{gg}^{-1}$ (1-53\% of total As extracted), being the predominant species in the Wakame sample from Spain. In the case of $\mathrm{PO}_{4}$-sug, concentrations ranged from 0.1 to $22 \mu \mathrm{gg}^{-1}(0.6-93 \%$ of total As extracted) and it is the major species in the Wakame sample from Japan, as well as in both Nori samples. $\mathrm{SO}_{3}$-sug was only detected in Fucus (Fig. 3b), Sea spaghetti and Hijiki (Fig. 3c) samples, at concentration levels between 0.6 and $4.2 \mu \mathrm{gg}^{-1}(1-23 \%$ of total As extracted), whereas $\mathrm{SO}_{4}$-sug was only detected in Fucus $\left(7.2 \mu \mathrm{gg}^{-1}\right)$ and Hijiki $\left(2.7 \mu \mathrm{gg}^{-1}\right)$ samples (Fig. 3b and c, respectively), representing 4 and $20 \%$ of total As extracted, respectively. Therefore, it is remarkable that arsenosugars were the only arsenic species that could be detected in the water extracts of Nori from Spain, $\mathrm{PO}_{4}$-sug being the major species, followed by Gly-sug, as it was reported by Wei et al. [8], although DMA was also detected in Nori from Japan. In brown algae, toxic arsenic species (low concentration levels of DMA and considerably high concentration levels of As $(V))$ were detected together with arsenosugars.

In arsenic speciation studies, mass balance between total arsenic concentration and the total arsenic extracted provides an estimation of the extraction yield. For quality assessment, column recovery must also be established to guarantee the suitability of the chromatographic separation. With this aim, the ratios of the sum of the concentrations of the species eluted from the chromatographic column with the total arsenic concentration in the extract injected into the column were calculated. The values obtained for column recoveries are also shown in Table 4 and ranged between 55 and $101 \%$, depending on the alga species and their origin. Low column recoveries could indicate the presence of species different from those studied, which cannot be detected with the chromatographic separations used, such as arsenic species present at concentration

Table 4

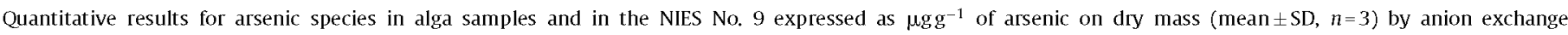
HPLC-(UV)-HG-AFS, and total arsenic extracted determined by ICP-AES.

\begin{tabular}{|c|c|c|c|c|c|c|c|c|c|c|}
\hline \multirow[t]{2}{*}{ Alga } & \multirow[t]{2}{*}{ Origin } & \multirow{2}{*}{$\begin{array}{l}\text { Total As } \\
\text { extracted }\end{array}$} & \multirow{2}{*}{$\begin{array}{l}\text { Extraction } \\
\text { efficiency }(\%)^{b}\end{array}$} & \multicolumn{6}{|l|}{ Arsenic species } & \multirow{2}{*}{$\begin{array}{l}\text { Column } \\
\text { recovery }(\%)^{c}\end{array}$} \\
\hline & & & & DMA & $\mathrm{As}(\mathrm{V})$ & Gly-sug & $\mathrm{PO}_{4}$-sug & $\mathrm{SO}_{3}$-sug & $\mathrm{SO}_{4}$-Sug & \\
\hline Arame & Japan & $20 \pm 2$ & $77 \pm 8$ & $0.48 \pm 0.04$ & $7.0 \pm 0.1$ & $1.5 \pm 0.1$ & $2.04 \pm 0.01$ & n.d. & n.d. & $55 \pm 5$ \\
\hline Fucus & France & $36 \pm 2$ & $76 \pm 5$ & $0.55 \pm 0.07$ & $11 \pm 1$ & $2.6 \pm 0.1$ & $0.8 \pm 0.1$ & $0.6 \pm 0.1$ & $7.2 \pm 0.1$ & $63 \pm 4$ \\
\hline Sea spaghetti & Spain & $18 \pm 2$ & $75 \pm 9$ & n.d. & $2.0 \pm 0.1$ & $4.5 \pm 0.4$ & $0.11 \pm 0.01$ & $4.2 \pm 0.9$ & n.d. & $60 \pm 8$ \\
\hline Hijiki & Japan & $72 \pm 1$ & $73 \pm 4$ & $0.44 \pm 0.06$ & $50.3 \pm 0.4$ & $1.05 \pm 0.03$ & $0.4 \pm 0.1$ & $0.7 \pm 0.1$ & $2.7 \pm 0.4$ & $77 \pm 1$ \\
\hline \multirow{3}{*}{ Kombu } & France & $39 \pm 2$ & $93 \pm 9$ & $0.40 \pm 0.04$ & $24 \pm 1$ & $3.1 \pm 0.2$ & $4.04 \pm 0.04$ & n.d. & n.d. & $81 \pm 5$ \\
\hline & Japan & $72 \pm 2$ & $74 \pm 5$ & $0.36 \pm 0.03$ & $32 \pm 3$ & $4.7 \pm 0.3$ & $22 \pm 1$ & n.d. & n.d. & $82 \pm 5$ \\
\hline & Spain & $40 \pm 2$ & $87 \pm 9$ & n.d. & $11 \pm 2$ & $11 \pm 3$ & $1.9 \pm 0.3$ & n.d. & n.d. & $60 \pm 9$ \\
\hline Laminaria & France & $92 \pm 2$ & $73 \pm 3$ & n.d. & $77 \pm 3$ & $10.2 \pm 0.7$ & $3.5 \pm 0.1$ & n.d. & n.d. & $99 \pm 4$ \\
\hline \multirow[t]{2}{*}{ Wakame } & Japan & $18 \pm 3$ & $49 \pm 8$ & $0.025 \pm 0.007$ & $4.5 \pm 0.3$ & $2.68 \pm 0.03$ & $10.10 \pm 0.05$ & n.d. & n.d. & $96 \pm 16$ \\
\hline & Spain & $27 \pm 3$ & $73 \pm 8$ & n.d. & $2.2 \pm 0.1$ & $14.3 \pm 0.2$ & $1.5 \pm 0.1$ & n.d. & n.d. & $67 \pm 7$ \\
\hline \multirow[t]{2}{*}{ Nori } & Japan & $14 \pm 2$ & $61 \pm 9$ & $0.064 \pm 0.005$ & n.d. & $1.02 \pm 0.07$ & $13 \pm 1$ & n.d. & n.d. & $101 \pm 16$ \\
\hline & Spain & $25 \pm 3$ & $74 \pm 9$ & n.d. & n.d. & $1.6 \pm 0.1$ & $20.1 \pm 0.3$ & n.d. & n.d. & $87 \pm 10$ \\
\hline Sargasso $^{a}$ & - & $107 \pm 2$ & $98 \pm 2$ & $0.9 \pm 0.1$ & $70 \pm 1$ & $1.0 \pm 0.2$ & $1.4 \pm 0.2$ & n.d. & $7 \pm 2$ & $75 \pm 2$ \\
\hline
\end{tabular}

a Sargassum fulvellum (CRM NIES No. 9).

b Calculated as the ratio between the total As extracted concentration and the total As in digested samples (Table 2).

c Calculated as the ratio between the sum of As species concentrations and the total As concentration in the extract. n.d. $=$ not detected. 

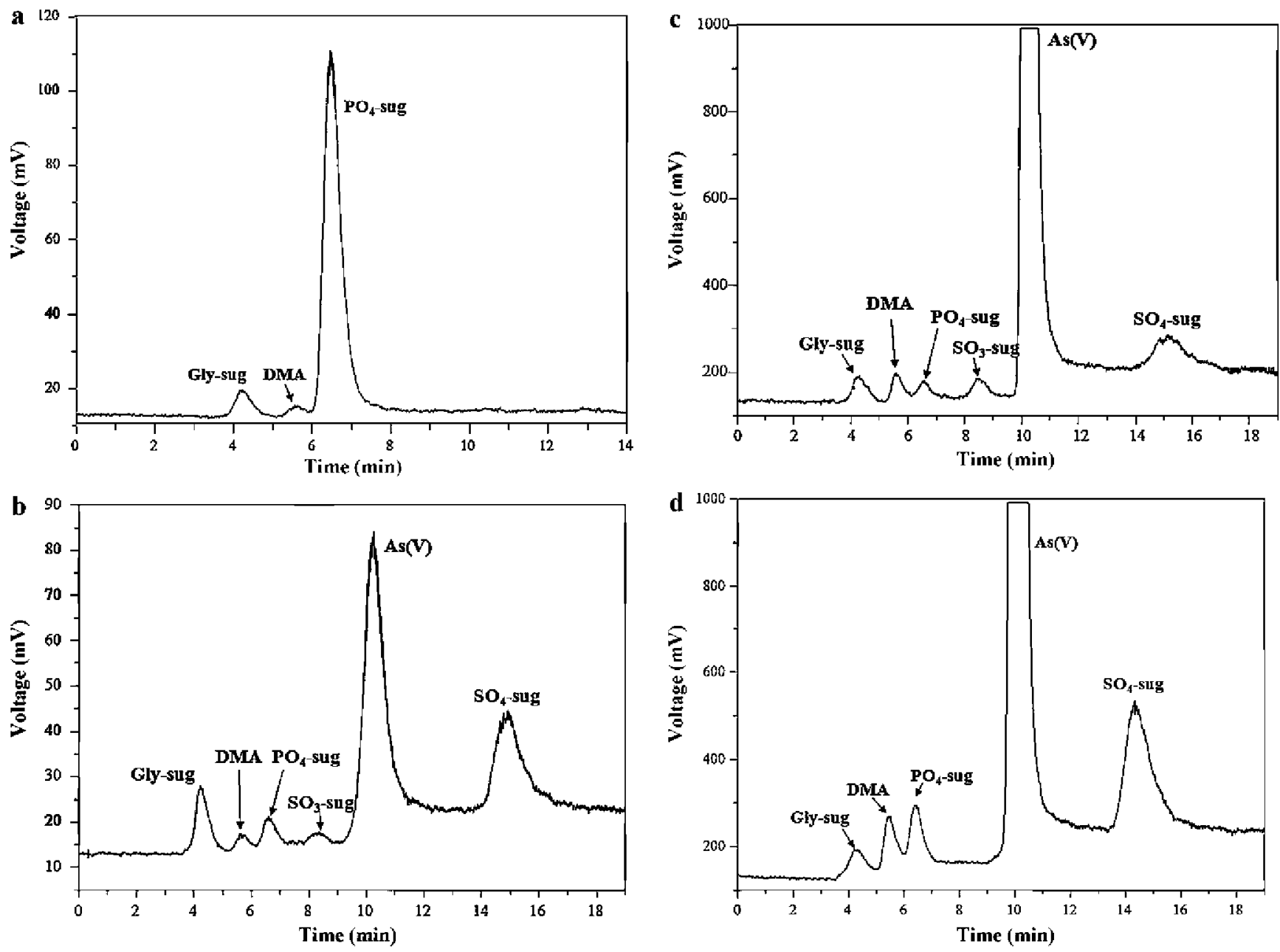

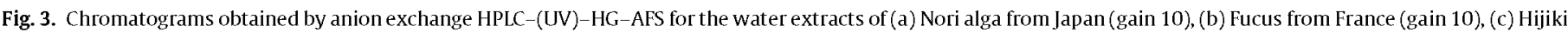
from Japan (gain 100) and (d) the NIES No. 9 Sargasso material (gain 100).

levels lower than the LOD of the developed methods or arsenic species that are not able to elute from the analytical column, for example macromolecules such as arsenic bound to water soluble proteins [41].

The comparison between arsenic species found in the same alga species, from different origins, is interesting (Table 4). In both Nori samples, a similar pattern can be observed, since $\mathrm{PO}_{4}$-sug was the major species ( 80 and $93 \%$ of total As extracted in Nori from Spain and Japan, respectively) and $A s(V)$ was not detected. However, DMA was found only in Nori from Japan, but at a very low concentration level $\left(0.064 \mu \mathrm{gg}^{-1}\right)$, despite its lower total As (Table 2) and total As extracted concentrations (Table 4). High column recoveries were found for both samples (101 and $87 \%$ for Nori from Japan and Spain, respectively). Therefore, most of the arsenic extracted was identified as species in Nori samples.

On the other hand, different patterns were observed for Kombu and Wakame samples from different origins. In the case of Wakame, very different extraction efficiencies were found (Table 4), despite the same total As concentration (Table 2). Regarding arsenic species, $\mathrm{As}(\mathrm{V})$ and two arsenosugars (Gly-sug and $\mathrm{PO}_{4}$-Sug) were detected in both samples, but DMA was again only detected in the alga from Japan. The most remarkable difference is about the predominant species, which were Gly-sug in Wakame from Spain (53\% of total As extracted) and $\mathrm{PO}_{4}$-sug in Wakame from Japan (56\% of total As extracted). As(V) was found at a lower concentration level in Wakame from Spain than in Wakame from Japan, accounting for
8 and $25 \%$ of total As extracted, respectively. Column recovery was quantitative in Wakame from Japan (96\%), but it was considerably lower in the sample from Spain (67\%). This fact could be related with the higher extraction efficiency found in the alga from Spain, since the sum of arsenic concentrations found as species were similar for both samples (about $18 \mu \mathrm{gg}^{-1}$ of arsenic). Therefore, part of the water soluble arsenic species in Wakame from Spain could not be identified with the method used.

With regard to Kombu, As(V) and two arsenosugars (Gly-sug and $\mathrm{PO}_{4}$-sug) were detected in the three alga samples, and DMA was only detected in the algae from France and Japan, but not in the sample from Spain. Therefore, the three Kombu samples presented the same arsenic species, with the exception of DMA; however, considerable differences were found in species concentration levels. $\mathrm{As}(\mathrm{V})$ was the major species in the three alga samples, accounting for 62, 44 and $28 \%$ of total As extracted in Kombu from France, Japan and Spain, respectively (Table 4). Regarding arsenosugars, Gly-sug and $\mathrm{PO}_{4}$-sug concentration levels were similar in Kombu from France ( 8 and $10 \%$ of total arsenic extracted, respectively), whereas $\mathrm{PO}_{4}$-sug concentration was considerably higher in Kombu from Japan (30\% of total As extracted) and Gly-sug was the predominant arsenosugar in Kombu from Spain, together with As(V) (28\% of total As extracted). Considering total arsenic concentration, samples from France and Spain presented a similar total arsenic concentration level (Table 2), but it was approximately two times higher in Kombu from Japan. This higher total arsenic concentration 
was not reflected in a considerable increase in $\mathrm{As}(\mathrm{V})$ concentration, but in $\mathrm{PO}_{4}$-sug concentration, which was about five and ten times higher than in Kombu from France and Spain, respectively. On the other hand, column recoveries were higher for the samples from France and Japan (about $80 \%$ ) than for the sample from Spain (60\%). In conclusion, the differences found between the same alga species from different origins seem to be more pronounced for brown alga than red alga samples, and are more noticeable regarding arsenic species concentration levels than the species identified.

Arsenic speciation analysis of Sargasso material (Fig. 3d, Table 4) showed the predominant presence of $A s(V)$ (65\% of the extracted As), which is in agreement with previous studies [10,21,42]. Furthermore, DMA and three arsenosugars (Gly-sug, $\mathrm{PO}_{4}$-sug and $\mathrm{SO}_{4}$-sug) were detected and quantified in this study. Ruiz-Chancho et al. [42] and Llorente-Mirandes et al. [21] also reported the presence in this $\mathrm{CRM}$ of $\mathrm{SO}_{3}$-sug, in a concentration of approximately $2 \mu \mathrm{g} \mathrm{g}^{-1}$. However, this arsenosugar was not detected in the present study. On the other hand, the column recovery found was $75 \%$, so a part of the arsenic extracted was not identified as species.

Arsenic in alga samples studied is present under different chemical forms, with different toxicities. Therefore, from the results obtained, total arsenic content is not a useful parameter in the assessment of the toxicological implications derived from the consumption of edible algae. In Spanish legislation they are included in the canned vegetables group, for which the maximum established limit of total arsenic is $1 \mu \mathrm{gg}^{-1} \mathrm{dw}$ [43]. However, this restrictive legislation for total arsenic is not appropriate for algae, since they are primary arsenic accumulators in the marine environment, as well as an important stage of arsenic metabolism through the food chain. Therefore, the determination of toxic arsenic species, especially inorganic arsenic, is necessary. At this regard, arsenic concentration present in edible algae is limited in a few countries on the basis of the inorganic arsenic concentration levels. Thus, regulations in France and the United States has maximum permissible limits of $3 \mu \mathrm{g} \mathrm{g}^{-1} \mathrm{dw}$ inorganic arsenic [44], whereas in Australia and New Zealand the limit is lower $\left(1 \mu \mathrm{g} \mathrm{g}^{-1} \mathrm{dw}\right)$ [45]. Nori samples (red algae) did not exceed these values. However, they were exceeded by all the brown alga samples analyzed, although Sea spaghetti and Wakame from Spain did not exceed the maximum limit of $3 \mu \mathrm{g} \mathrm{g}^{-1} \mathrm{dw}$ admitted by the regulations in France and the USA. Therefore, most of the alga samples analyzed could not be sold in these countries. It was reported that some algae from different origins were withdrawn from the French market because their inorganic arsenic concentration was higher than $3 \mu \mathrm{gg}^{-1} \mathrm{dw}$ [46]. The absence of legislation on this point in other countries means that they are likely to receive products that are denied entrance into other markets owing to legislation. From the point of view of health considerations, the absence of data concerning the consumption of algae in Western countries makes it difficult to calculate intake levels, and most estimates are based on the consumption of the population of Japan, with a daily average consumption of brown algae of $2-3 \mathrm{~g} \mathrm{dw}$ and a maximum consumption of $12 \mathrm{~g} \mathrm{dw}$ [14]. For Hijiki and Laminaria, taking into account the mean concentration consumption $\left(3 \mathrm{gday}^{-1}\right)$ and the arsenate concentration reported in Table 4 , the intake of inorganic arsenic would be 151 and $231 \mu \mathrm{g} \mathrm{day}^{-1}$, respectively, values close to or slightly higher than the tolerable daily intake (TDI) of $150 \mu \mathrm{g}$ inorganic arsenic day ${ }^{-1}$ for an adult weighing $70 \mathrm{~kg}$ established by the World Health Organization (WHO) [47]. Therefore, these algae could be considered a health risk.

\subsection{Stability of arsenic species during the extraction procedure}

In any elemental speciation study, it is important to investigate whether the individual species are altered during any step of the method in order to confirm the reliability of the proposed analytical method. For this purpose, reference materials certified for arsenic species of interest would be ideal. However, the certified reference materials frequently used in arsenic speciation studies in alga samples have no certified values for the arsenic compounds. Therefore, spiking of alga material was used to assess the stability of arsenic species during the extraction procedure. In a previous work [10], spiking studies showed that As(III), As(V), MMA and DMA remained stable during the extraction procedure, since between 93 and $115 \%$ of the spiked arsenic species were recovered. In the present study, the stability of AsB, TETRA and TMAO were assessed to confirm that their absence in alga samples was not due to possible transformations between arsenic species during the extraction process. Recoveries obtained were $95 \pm 6 \%, 98 \pm 5 \%$ and $103 \pm 5 \%$, for AsB, TETRA and TMAO, respectively. Therefore, the absence of significant losses or transformations of arsenic species evaluated during the sample treatment could be confirmed. It was not possible to perform spiking studies of arsenosugar species, due to the absence of standard solutions which led us to the addition of appreciable concentration levels of these species on alga samples. However, since the four arsenosugars could be detected in alga samples and the rest of the arsenic species studied remaining stable during the sample treatment, it can be considered that these arsenic species are likely to remain stable as well. This is in agreement with Tukai et al. [7] and Wei et al. [8], who reported that arsenosugars were stable during $5 \mathrm{~min}$ at $70^{\circ} \mathrm{C}$ and a short-term heating at $100^{\circ} \mathrm{C}$, respectively.

\section{Conclusions}

The results obtained in the present study contribute to increase the existing data on the presence of arsenic compounds in marine alga samples, especially those used for human consumption. Taking into account the considerably high arsenate concentration levels found in brown edible algae, the development of robust and reliable arsenic speciation methods is of interest to highlight the need to introduce appropriate harmonized legislation to limit the inorganic arsenic content in these food products.

\section{Acknowledgements}

This work was financially supported by the Universidad Politécnica de Madrid (project 188/Q105815-102) and Ministerio de Educación y Ciencia (project CTM2007-66432). The authors thank Dr. Kevin A. Francesconi for the kind donation of the Fucus serratus extract, as well as the Centre d'Etude et de Valorisation des Algues (Pleubian, France) for the kind donation of Fucus vesiculosus, Laminaria ochroleuca and Laminaria digitata.

\section{References}

[1] J.C. Ng, Environ. Chem. 2 (2005) 146-160.

[2] J.S. Edmonds, K.A. Francesconi, in: P.J. Craig (Ed.), Organometallic Compounds in the Environment, second ed., Wiley, New York, 2003, pp. 195-222.

[3] M. Leermakers, W. Baeyens, M. De Gieter, B. Smedts, C. Meert, H.C. De Bisschop, R. Morabito, P. Quevauviller, TrAC Trends Anal. Chem. 25 (2006) 1-10.

[4] K.A. Francesconi, J.S. Edmonds, Adv. Inorg. Chem. 44 (1997) 147-189.

[5] D. Kuehnelt, K.J. Irgolic, W. Goessler, Appl. Organomet. Chem. 15 (2001) 445-456.

[6] G. Raber, K.A. Francesconi, K.J. Irgolic, W. Goessler, Fresen. J. Anal. Chem. 367 (2000) 181-188.

[7] R. Tukai, W.A. Maher, I.J. McNaught, M.J. Ellwood, Anal. Chim. Acta 457 (2002) $173-185$

[8] C. Wei, W. Li, C. Zhang, M. Van Hulle, R. Cornelis, X. Zhang, J. Agric. Food Chem. 51 (2003) 5176-5182.

[9] S. García Salgado, M.A. Quijano Nieto, M.M. Bonilla Simón, Talanta 68 (2006) $1522-1527$.

[10] S. García Salgado, M.A. Quijano Nieto, M.M. Bonilla Simón, J. Chromatogr. A 1129 (2006) 54-60.

[11] W. Li, C. Wei, C. Zhang, M. Van Hulle, R. Cornelis, X. Zhang, Food Chem. Toxicol. 41 (2003) 1103-1110. 
[12] J.J. Sloth, E.H. Larsen, K. Julshamn, J. Anal. Atom. Spectrom. 18 (2003) 452-459. [13] V.K. Sharma, M. Sohn, Environ. Int. 35 (2009) 743-759.

[14] T. Sakurai, T. Kaise, T. Ochi, T. Saitoh, C. Matsubara, Toxicology 122 (3) (1997) $205-212$.

[15] J. Feldmann, E.M. Krupp, Anal. Bioanal. Chem. 399 (2011) 1735-1741.

[16] K.A. Francesconi, R. Tanggaard, C. McKenzie, W. Goessler, Clin. Chem. 48 (1) 2002) $92-101$

[17] C. Niegel, F.M. Matysik, Anal. Chim. Acta 657 (2010) 83-99.

[18] Z. Gong, X. Lu, M. Ma, C. Watt, X.C. Le, Talanta 58 (2002) 77-96.

[19] S. McSheehy, J. Szpunar, R. Morabito, Ph. Quevauviller, TrAC Trends Anal. Chem. 22 (2003) 191-209.

[20] K.A. Francesconi, D. Kuehnelt, Analyst 129 (2004) 373-395.

[21] T. Llorente-Mirandes, M.J. Ruiz-Chancho, M. Barbero, R. Rubio, J.F. LópezSánchez, Chemosphere 81 (2010) 867-875.

[22] D. Sânchez-Rodas, W.T. Corns, B. Chen, P.B. Stockwelll, J. Anal. Atom. Spectrom. 25 (2010) 933-946.

[23] Y.W. Chen, N. Belzile, Anal. Chim. Acta 671 (2010) 9-26.

[24] J.L. Gómez-Ariza, D. Sánchez-Rodas, R. Beltrán, W. Corns, P. Stockwell, Appl. Organomet. Chem. 12 (1998) 439-447.

[25] J.L. Gómez-Ariza, D. Sánchez-Rodas, I. Giráldez, E. Morales, Talanta 51 (2000) $257-268$.

[26] A.L. Lindberg, W. Goessler, M. Grandér, B. Nermell, M. Mahter, Toxicol. Lett. 168 (3) (2007) $310-318$.

[27] E. Schmeisser, W. Goessler, M. Kienzl, K.A. Francesconi, Anal. Chem. 76(2004) $418-423$.

[28] Z. Šlejkovec, J.T. van Elteren, A.R. Byrne, Talanta 49 (1999) 619-627.

[29] D. Sánchez-Rodas, A. Geiszinger, J.L. Gómez-Ariza, K.A. Francesconi, Analyst 127 (2002) 60-65.

[30] R. Schaeffer, C. Soeroes, I. Ipolyi, P. Fodor, N.S. Thomaidis, Anal. Chim. Acta 547 (2005) 109-118.
[31] Z. Šlejkovec, E. Kápolna, I. Ipolyi, J.T. van Elteren, Chemosphere 63 (2006) 1098-1105.

[32] W. Geng, R. Komine, T. Ohta, T. Nakajima, H. Takanashi, A. Ohki, Talanta 79 (2009) 369-375.

[33] A.D. Madsen, W. Goessler, S.N. Pedersen, K.A. Francesconi, J. Anal. Atom. Spectrom. 15 (2000) 657-662.

[34] S. García-Salgado, D. García-Casillas, M.A. Quijano-Nieto, M.M. Bonilla-Simón, Water Air Soil Pollut. (2011), doi:10.1007/s11270-011-0882-X.

[35] R. Domínguez-González, A. Moreda-Piñeiro, A. Bermejo-Barrera, P. BermejoBarrera, Talanta 66 (2005) 937-942.

[36] C. Almela, M. Jesus Clemente, D. Velez, R. Montoro, Food Chem. Toxicol. 44 (2006) 1901-1908.

[37] C. García-Sartal, V. Romarís-Hortas, M.C. Barciela Alonso, A. Moreda-Piñeiro, R Domínguez-González, P. Bermejo-Barrera, Microchem. J. 98 (2011) 91-96.

[38] M. Morita, Y. Shibata, Appl. Organomet. Chem. 4 (1990) 181-190.

[39] S. García Salgado, M.A. Quijano Nieto, M.M. Bonilla Simón, Talanta 75 (2008) 897-903.

[40] K.A. Francesconi, Appl. Organomet. Chem. 17 (2003) 682-683.

[41] T. Řezanka, K. Sigler, Phytochemistry 69 (2008) 585-606.

[42] M.J. Ruiz-Chancho, J.F. Lopez-Sanchez, R. Rubio, J. Appl. Phycol. 22 (2010) $465-472$

[43] Real Decreto, 2420/78, de junio, por el que se aprueba la Reglamentación técnico-sanitaria para la elaboraciôn y venta de conservas vegetables.

[44] S. Mabeau, J. Fleurence, Trends Food Sci. Technol. 4 (1993) 103-107.

[45] Australian New Zealand Food Authority (ANZFA), Food Standards Code, Issue $41,1997$.

[46] S. McSheehy, J. Szpunar, J. Anal. Atom. Spectrom. 15 (2000) 79-87.

[47] World Health Organization, Evaluation of Certain Food Additives and Contaminants, 33rd Report of the Joint FAO/WHO Expert Committee on Food Additives, WHO Technical Report Series 759, WHO, Geneva, Switzerland, 1989. 